\title{
Microrganismos e seus produtos de fermentação interferem na qualidade de sementes e plântulas de milho?
}

\author{
Álisson Queiroz MOURA ${ }^{1 *}$, Erikson Kadoshe de Morais RAIMUNDO ${ }^{1}$, \\ Barbara Chrys Gomes BALDUINO ${ }^{1}$, Ailsa Cristiane Arcanjo SOARES ${ }^{1}$, Victor Augusto FORTI ${ }^{1}$
}
${ }^{1}$ Programa de Pós-Graduação em Agroecologia e Desenvolvimento Rural, Universidade Federal de São Carlos, Araras, SP, Brasil. (Orcid: *; 0000-0001-7109-3273; 0000-0002-3364-2865; 0000-0003-0004-2246; 0000-0003-2599-3603) *E-mail: alissonq8@gmail.com (Orcid: 0000-0001-6421-8082)

Recebido em 10/12/2019; Aceito em 10/07/2020; Publicado em 31/07/2020.

\begin{abstract}
RESUMO: A microbiota do solo e suas funções ecológicas são responsáveis por relações diretas e indiretas com a planta. Objetivou-se avaliar a sanidade e germinação em sementes de milho, bem como a emergência e desenvolvimento de plântulas submetidas a microrganismos capturados de dois ambientes. Sementes de milho foram inoculadas ou irrigadas com microrganismos e seus produtos de fermentação, provenientes de duas áreas (mata ou cultivo de cana-de-açúcar) sob diferentes concentrações e avaliadas quanto a porcentagem de germinação, índice de velocidade de germinação, sanidade em teste em BOD, além da emergência, altura de plântula, massa de matéria seca da parte aérea e raiz e volume de raiz em ensaios em bandejas com solo. Não houve comprometimento na germinação, independentemente do tratamento utilizado. Houve a mitigação de Aspergillus spp. e Penicillium spp., porém, a potencialização de Fusarium spp em condições de laboratório sob aplicação de 50 e 100\% de microrganismos capturados da área de mata e cana. De forma geral, houve efeito negativo da aplicação do tratamento sobre os parâmetros fisiológicos, provocados provavelmente por desequilíbrio na ecologia microbiana associado a sementes e plântulas.
\end{abstract}

Palavras-chave: Fusarium spp.; microrganismos eficientes; ecossistemas.

\section{Do microorganisms and their fermentation products interfer on seed and seedlings corn quality?}

\begin{abstract}
Soil microbiota and its ecological functions are responsible for direct and indirect relations with the plant. The aim of this study was to evaluate the corn seeds health and germination and seedling emergence and development submitted to microorganisms captured from two environments. Corn seeds were inoculated or irrigated with microorganisms and their fermentation products, coming from two areas (forest or sugarcane cultivation) under different concentrations and evaluated for the germination percentage, germination speed index, health in test in BOD, seedling emergence, seedling height, shoot and root dry matter mass, and root volume in soil tray tests. There was no effect on germination, regardless of the treatment used. There was mitigation of Aspergillus spp. and Penicillium spp., but the increase of Fusarium spp occurrence in laboratory conditions under concentration of 50 and $100 \%$ of microorganisms captured from the forest and sugarcane areas. In general, there was a negative effect of all treatments on physiological parameters, probably caused by an imbalance in the microbial ecology associated with seeds and seedlings.
\end{abstract}

Keywords: Fusarium spp.; efficient microorganisms; ecosystems.

\section{INTRODUÇÃO}

A microbiota do solo e suas funções ecológicas são responsáveis por relações diretas e indiretas com as plantas (FERREIRA et al., 2017) e interferem nos processos de desenvolvimento e produção vegetal (MORAES et al., 2018) e na interação patógeno-hospedeiro (PARIKH et al., 2018).

No entanto, é necessário compreender que estas relações não são estabelecidas ao acaso, uma vez que fatores intrínsecos da planta, como, estádio de desenvolvimento, diversidade de espécies e informações genéticas são responsáveis por seleções especificas de microrganismos (CHAPARRO et al., 2014). Estas relações são estabelecidas pelos próprios microrganismos e pela heterogeneidade do meio à qual estão inseridos (FERREIRA et al., 2017).

Dada à importância destas relações, a utilização de microrganismos no emprego da sustentabilidade agrícola tem se intensificado nos últimos anos, promovendo fatores positivos, como biorremediação em solos contaminados (COLLA et al., 2008), fixação biológica de nitrogênio (PEDROZO et al., 2018), controle biológico (MOHAMMED et al., 2019) e promoção de crescimento (GIASSI et al., 2016) em diversas culturas de interesse econômico, inclusive do milho.

A cultura do milho possui relevante importância econômica. De acordo com o United States Departament of Agriculture - USDA (2020), a produção mundial de milho na safra de 2018/19 foi de 1,1 bilhão de toneladas, sendo 101 milhões desse total proveniente da produção brasileira. Entretanto, esta cultura é severamente acometida por patógenos que habitam o solo, como o Fusarium spp., responsáveis por consideráveis perdas econômicas (PARIKH et al., 2018). Além disso, fungos como Aspergillus 
spp. e Penicillium spp. são comuns em sementes desta cultura, apresentando maior problema em pós-colheita, primordialmente pela produção de micotoxinas (TAHEUR et al., 2019).

Vários são os métodos de controles destes patógenos, como, utilização de variedades resistentes, rotação de cultura e, principalmente, o químico (JANSSEN et al., 2019; SAVIĆ et al., 2020). No entanto, frente à demanda por processos com menor impacto ambiental, o controle biológico tem se mostrado muito promissor, uma vez que possibilita a melhora da qualidade dos produtos, da saúde dos trabalhadores rurais e a redução da poluição, preservando os recursos ambientais (BÁNKUTI; BÁNKUTI, 2014).

Segundo He et al. (2019) o Trichoderma asperellum quando aplicado diretamente no solo em plântulas de milho controlou 53,7\% de Fusarium graminearum, responsável pela podridão do colmo. Estudos têm mostrado ainda que a combinação de bioplástico inoculado com Aspergillus flavus NRRL 30796 não aflatoxigênico, dispostos sobre solo que contém Aspergillus flavus toxigênicos mitigou em 80 a 92\% a contaminação de aflatoxina no milho (ACCINELLI et al., 2012).

Dentre várias premissas para o sucesso do controle biológico, podemos destacar a compreensão da ecologia microbiana e caracterização dos microrganismos. Fu et al. (2017) observaram que a aplicação de biofertilizante elaborado a partir de composto e Bacillus amyloliquefaciens NJN-6, em solos com Fusarium oxysporum $\mathrm{f}$ sp. cubense, alterou toda dinâmica do microbioma existente na rizosfera, aumentando a abundância e riqueza de bactérias e diminuído a abundância de fungos, fato que aumentou a incidência do mal-do-panamá, importante doença da bananeira.

O equilíbrio microbiano, bem como o seu local de origem tem grande influência no desenvolvimento da cultura implantada (MOWA; MAASS, 2012; FERREIRA et al., 2017). Fato que torna a prática de aplicação de Microrganismos Eficientes (EM) relevante para a agricultura. O EM é um produto fermentado a partir de microrganismos presentes em solos férteis e em plantas (CALEROHURTADO et al., 2019). Por se tratar de uma prática relativamente fácil e de custo reduzido, pode ser realizada para o tratamento de sementes.

O objetivo deste estudo foi avaliar se a sanidade e a germinação de sementes, bem como o desenvolvimento de plântulas de milho são afetadas pela inoculação de microrganismos coletados em dois ambientes em diferentes concentrações.

\section{MATERIAL E MÉTODOS}

O estudo foi desenvolvido no Laboratório de Agricultura Orgânica (LAO), da Universidade Federal de São Carlos - Araras/SP. Para tanto foram utilizadas sementes de milho (Zea mays L.), variedade AVARÉ, Lote 052/17, cedida pelo Laboratório Central de Sementes e Mudas (LSCM) da Coordenadoria de Desenvolvimento Rural Sustentável -SP (CDRS).

\subsection{Captura e ativação dos microrganismos eficientes}

A primeira etapa correspondeu à captura de microrganismos eficientes na mata e no monocultivo de cana-de-açúcar (cana) compreendidos na área do Centro de Ciências Agrárias - UFSCar/Araras-SP, latitude 2541'29”' e longitude $75^{\circ} 31^{\prime} 57^{\prime \prime}$. Para a captura dos microrganismos, bem como sua ativação, iscas a base de arroz cozido (700g) foram postas sobre o solo e retiradas após dez dias; os microrganismos capturados foram selecionados visualmente a partir de suas colorações, desprezando as partes cinza, marrom e preta (SANTOS et al., 2020). Após a captura, todo o arroz com os microrganismos foi colocado em garrafas, juntamente com caldo de cana-de-açúcar $(250 \mathrm{~mL})$ e água $(1750 \mathrm{~mL})$ e armazenados em temperatura ambiente. Após 25 dias, ao não observar mais produção de gás (termino da fermentação), o inóculo se encontrava disponível para uso.

\subsection{Preparo das concentrações}

A concentração de 100\% correspondeu ao inóculo sem adição de água, ou seja, em seu estado puro. Para tanto, as demais concentrações foram determinadas através do inóculo diluído em água.

\subsection{Inoculação de sementes}

Após a obtenção dos tratamentos, 50 sementes foram colocadas em saco de plástico junto à $5 \mathrm{~mL}$ de cada preparado nas concentrações pré-determinadas, homogeneizadas manualmente por 2 minutos em movimento rotacional sendo posteriormente colocadas para secar em temperatura ambiente sobre bandejas de plástico previamente higienizadas com álcool a $70 \%$.

Após a inoculação, as sementes foram avaliadas quanto a sua qualidade, por meio do teste de germinação, índice de velocidade de germinação e sanidade.

\subsection{Teste de Germinação e Índice de velocidade de germinação (IVG) \\ O esquema fatorial adotado foi $2 \times 5$, sendo 2 ambientes} de capturas dos microrganismos (mata e cana) e 5 concentrações $(0,25 ; 50 ; 75$ e 100\%), em que cada tratamento se constituiu de 4 repetições com 50 sementes cada, para cada um dos testes. As sementes, após inoculação, foram distribuídas em duas folhas de papel tipo germitest, umedecido com quantidade de água equivalente a 2,5 vezes o seu peso e cobertas com mais uma folha para a confecção dos rolos. Após preparo dos rolos, estes foram acondicionados em câmara tipo BOD regulada a $25^{\circ} \mathrm{C}$ e as avaliações foram realizadas ao quinto e sétimo dia após a instalação do teste, computando-se a porcentagem de plântulas normais (BRASIL, 2009a).

Para calcular o índice de velocidade de germinação (IVG), foi utilizada a fórmula proposta por Maguire (1962): $I V G=G_{1} / N_{1}+G_{2} / N_{2}+\ldots G_{n} / N_{n}$, onde: $G_{1}, G_{2}, G_{n}=$ número de plântulas germinadas na primeira até a última contagem e $\mathrm{N}_{1}, \mathrm{~N}_{2}, \mathrm{~N}_{\mathrm{n}}=$ número de semanas desde a primeira até a última contagem, considerando-se como sementes germinadas àquelas que apresentavam tamanho de raiz primária igual ou superior a $5 \mathrm{~mm}$.

\subsection{Teste de Sanidade}

Para o teste de sanidade foi considerado o esquema fatorial $2 \times 3$, sendo os ambientes de captura dos microrganismos (mata e cana) e 3 concentrações (0; 50 e $100 \%$ ), onde cada tratamento constituiu de 4 repetições com 25 sementes.

As sementes foram distribuídas em placas de Petri contendo duas folhas de papel de filtro $(0,16 \mathrm{~mm})$ umedecidas com água destilada, sendo que cada repetição foi composta por duas placas para diminuir a densidade e 
facilitar a identificação dos sinais dos patógenos. As placas foram acondicionadas em câmara tipo $\mathrm{BOD}$ regulada à $20^{\circ} \mathrm{C}$ onde permaneceram durante 7 dias (BRASIL, 2009b).

Passados os sete dias, avaliou-se a incidência (\%) de patógenos presentes nas sementes do milho, identificados a nível de gênero através de suas características morfológicas (FERREIRA DE SÁ et al., 2019).

\subsection{Ensaio de Emergência e Desenvolvimento de plântulas}

Para esse teste, considerou-se um fatorial duplo $2 \times 5$, sendo 2 ambientes de capturas dos microrganismos (mata e cana) e 5 concentrações $(0,25 ; 50 ; 75$ e 100\%), sob duas formas de aplicação (inoculação e irrigação). Os tratamentos foram compostos de 4 repetições com 50 sementes cada, avaliadas durante uma semana com intervalo de 48 horas entre as coletas de dados. O ensaio foi conduzido em ambiente protegido sob cobertura de telhado

Para tanto se utilizou bandejas de plástico perfuradas contendo $2100 \mathrm{~g}$ de um Latossolo Vermelo Distrófico com as seguintes características químicas, $\mathrm{pH}: 5\left(\mathrm{CaCl}_{2}\right)$; M.O: 33 $\mathrm{g} / \mathrm{dm}^{3}$; CTC: 49,6 mmolc/dm 3 ; V\%: 33; P (Resina): 5 $\mathrm{mg} / \mathrm{dm}^{3} ; \mathrm{H}+\mathrm{Al}: 33 \mathrm{mmolc} / \mathrm{dm}^{3} ; \mathrm{K}: 2,6 \mathrm{mmolc} / \mathrm{dm}^{3} ; \mathrm{Ca}$ : $8 \mathrm{mmolc} / \mathrm{dm}^{3}$ e $\mathrm{Mg}: 6 \mathrm{mmolc} / \mathrm{dm}^{3}$, respectivamente.

Foram avaliadas duas maneiras de aplicação dos microrganismos capturados, sendo via inoculação de sementes como proposto no item 2.3 e via irrigação. Para o tratamento via irrigação foi utilizada uma solução composta de água e dos produtos fermentados (25, 50, 75 e 100\%) em um volume final de $550 \mathrm{~mL}$. Apesar da irrigação com os tratamentos serem estabelecidos a cada sete dias, a irrigação convencional (apenas água) foi realizada para todos os tratamentos e testemunha sempre que houve necessidade.

As variáveis avaliadas foram: emergência de plântula (E.P) considerando-se como emersas as plântulas que apresentavam no mínimo dois centímetros de altura e índice de velocidade de emergência (IVE) da mesma maneira descrita para o IVG. Em relação ao desenvolvimento das plantas, determinou-se a altura, utilizando-se de uma régua milimétrica desde a superfície do solo até o final da ponta da folha mais jovem. Após 21 dias, caracterizando o final das coletas de desenvolvimento, as plantas foram colhidas e realizadas a determinação do volume de raiz, por meio da diferença de volume de água (MARTINS et al., 2011), massa de matéria seca da parte aérea (MSPA) e raiz (MSR), determinados a partir da secagem em estufa de circulação de ar forçado a $65{ }^{\circ} \mathrm{C}$ até atingirem a massa constante com posterior pesagem em balança analítica e com os resultados expressos em gramas.

\subsection{Análise estatística}

Os dados foram submetidos ao teste de normalidade de Shapiro Wilk e homogeneidade de variâncias de Bartllet e, posteriormente, à ANOVA. Quando houve efeito significativo, as médias foram comparadas pelo teste de Tukey $(p<0,05)$ e as variáveis do ensaio de emergência e desenvolvimento de plântulas foram submetidas a análise de regressão com auxílio do programa estatístico SigmaPlot ${ }^{\circledR}$ versão 12 (SYSTAT SOFTWARE, 2012).

\section{RESULTADOS}

\subsection{Germinação, Índice de Velocidade de Germinação (IVG) e Sanidade}

Não houve diferença estatística para os efeitos isolados ou entre as interações para a germinação e o índice de velocidade de germinação (IVG) (Tabela 1).

Para a avaliação de sanidade houve diferença $(p<0,01)$ entre os efeitos isolados e suas interações (Tabela 2), quando se avaliou a incidência de Aspergillus spp., Penicillium spp., e Fusarium spp. em sementes de milho.

A inoculação com os microrganismos capturados da mata e cana promoveu a inibição na incidência de Aspergillus spp., e Penicillium spp. quando comparado a testemunha (Tabela 3 ). No entanto independente do ambiente de captura, ambos os inóculos promoveram o aumento na incidência de Fusarium spp. (Tabela 3).

\subsection{Emergência e Desenvolvimento de Plântula}

Quando as sementes foram tratadas via inoculação, houve diferença $(\mathrm{p}<0,05$ e $\mathrm{p}<0,01)$ para todas as variáveis na interação entre os inóculos dos diferentes ambientes de captura e concentrações (Tabela 4).

Tabela 1. Resumo da análise de variância para os efeitos principais e suas interações, referente à germinação e índice de velocidade de germinação (IVG).

Table 1. Summary of variance analysis for the main effects and their interactions, referring to germination and germination speed index (IVG).

\begin{tabular}{|c|c|c|c|}
\hline \multirow[b]{2}{*}{ Fonte de variação } & \multicolumn{2}{|c|}{ Germinação } & IVG \\
\hline & GL & P-valor & P-valor \\
\hline Ambiente captura (A) & 1 & $0,050^{\mathrm{ns}}$ & $0,443^{\mathrm{ns}}$ \\
\hline Concentrações (C) & 4 & $0,387^{\mathrm{ns}}$ & $0,079 \mathrm{~ns}$ \\
\hline Interação A x C & 4 & $0,623^{\mathrm{ns}}$ & $0,550^{\mathrm{ns}}$ \\
\hline $\mathrm{CV}(\%)$ & & 6,12 & 6,76 \\
\hline
\end{tabular}

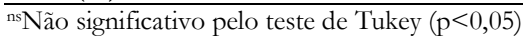

Tabela 2. Resumo da análise de variância para os efeitos principais e suas interações, referente à sanidade das sementes de milho avaliadas pela incidência de Aspergillus spp., Penicillium spp. e Fusarium spp.

Table 2. Summary of variance analysis for the main effects and their interactions, referring to the health of corn seeds evaluated by the incidence of Aspergillus spp., Penicillium spp. and Fusarium spp.

\begin{tabular}{lcc}
\hline & \multicolumn{2}{c}{ Aspergillus spp } \\
\cline { 2 - 3 } Fonte de Variação & GL & P-valor \\
\hline Ambiente de captura (A) & 1 & $0,0008^{* *}$ \\
Concentração (C) & 2 & $<0,0001^{* *}$ \\
Interação A x C & 2 & $0,022^{* *}$ \\
\hline CV (\%) & & 9,99 \\
\hline & GL & Penicillium spp \\
Fonte de Variação & 1 & P-valor \\
\hline Ambiente de captura (A) & 2 & $<0,0001 * *$ \\
Concentração (C) & 2 & $0,00001^{* *}$ \\
Interação A x C & & 9,99 \\
\hline CV (\%) & & Fusarium spp \\
\hline & GL & P-valor \\
Fonte de Variação & 1 & $<0,0001^{* *}$ \\
\hline Ambiente de captura (A) & 2 & $<0,0001^{* *}$ \\
Concentração (C) & 2 & $0,0006^{* *}$ \\
Interação A x C & & 4,53 \\
\hline CV (\%) & & \\
\hline$* *$ Significativo pelo teste de Tukey (p<0,01). & \\
& &
\end{tabular}


Tabela 3. Porcentagem de incidência de Aspergillus spp, Penicillium spp e Fusarium spp em sementes de milho inoculadas com microrganismos capturados da mata e monocultivo de cana em diferentes concentrações.

Table 3. Percentage of incidence of Aspergillus spp, Penicillium spp and Fusarium spp in corn seeds inoculated with microorganisms captured from the forest and monoculture of sugarcane at different concentrations.

\begin{tabular}{ccc}
\hline & \multicolumn{2}{c}{ Aspergillus spp } \\
\cline { 2 - 3 } Tratamentos $(\%)$ & Mata & Cana \\
\hline 0 & $10,25 \mathrm{aA}$ & $10,25 \mathrm{aA}$ \\
50 & $1,00 \mathrm{aB}$ & $1,00 \mathrm{aB}$ \\
100 & $0,50 \mathrm{aC}$ & $0,50 \mathrm{aC}$ \\
\hline & \multicolumn{2}{c}{ Penicillium spp } \\
\cline { 2 - 3 } Tratamentos $(\%)$ & Mata & Cana \\
\hline 0 & $16,75 \mathrm{aA}$ & $16,75 \mathrm{aA}$ \\
50 & $1,75 \mathrm{bB}$ & $4,25 \mathrm{aB}$ \\
100 & $1,00 \mathrm{bB}$ & $3,75 \mathrm{aB}$ \\
\hline & \multicolumn{2}{c}{ Fusarium $\mathrm{spp}$} \\
\hline Tratamentos $(\%)$ & Mata & Cana \\
\hline 0 & $17,50 \mathrm{aC}$ & $17,50 \mathrm{aB}$ \\
100 & $24,75 \mathrm{aB}$ & $22,00 \mathrm{bA}$ \\
& $26,75 \mathrm{aA}$ & $22,50 \mathrm{bA}$ \\
\hline
\end{tabular}

Médias seguidas das mesmas letras, minúsculas para linhas e maiúsculas para coluna não diferem pelo teste de Tukey $(\mathrm{p}<0,01)$.

A aplicação via inoculação dos microrganismos capturados na mata promoveu redução linear para todas as variáveis de avaliação de plântulas, exceto para a massa de matéria seca de raiz. Com exceção da altura de plântula, os dados obtidos com aplicação via inoculação dos microrganismos capturados do monocultivo de cana se ajustaram melhor ao modelo de regressão quadrático, apresentando as maiores médias de $96 \%$ de emergência (em 25\% do inóculo); 27,93 de IVE (em 50\% do inóculo); 3,11g de massa de matéria seca de parte aérea (em 25\% do inóculo) e77,7 mL de volume de raiz (em 25\% do inóculo) (Figura 1A; Figura 1B; Figura 1D e Figura 1E).

Para a massa de matéria seca da raiz, os dados se ajustaram melhor ao modelo de regressão quadrático, com 7,50 e 7,34g na concentração de $25 \%$ para os inóculos capturados no monocultivo de cana e mata, respectivamente (Figura 1F).

Quando o experimento foi conduzido com os tratamentos de irrigação, houve diferença $(\mathrm{p}<0,05$ e $\mathrm{p}<0,01)$ para todas as variáveis na interação entre os inóculos dos diferentes ambientes de captura e concentrações, exceto para emergência de plântula (Tabela 5).

Todas as variáveis analisadas foram negativamente influenciadas pelo aumento das concentrações do inóculo, independente do ambiente de captura (mata e cana) (Figura 2), ajustando-se melhor ao modelo de regressão linear.

Quando irrigado com inóculo da mata na concentração de $100 \%$, a emergência de plântula reduziu para 48\% se comparado com $90 \%$ da testemunha (Figura 2A), além de inibir em mais de $100 \%$ a altura das plântulas, massa seca da parte aérea, volume de raiz e massa seca da raiz (Figura 2B, Figura 2D, Figura 2E e Figura 2F).

Tabela 4. Resumo da análise de variância para os efeitos principais e suas interações, referente ao tratamento inoculado, avaliando os parâmetros emergência de plântula (EG), índice de velocidade de emergência (IVE), altura de plântula (AP), massa seca da parte aérea (MSPA), volume de raiz (VR) e massa seca de raiz (MSR).

Table 4. Summary of variance analysis for the main effects and their interactions, referring to inoculated treatment, evaluating seedling emergence (EG), emergence velocity index (IVE), seedling height (AP), shoot dry mass (MSPA), root volume (VR) and root dry mass (MSR).

\begin{tabular}{|c|c|c|c|c|c|c|c|}
\hline & & $\mathrm{EG}$ & IVE & $\mathrm{AP}$ & MSPA & VR & MSR \\
\hline Fonte de variação & GL & P-valor & P-valor & P-valor & P-valor & P-valor & P-valor \\
\hline Ambiente de captura (A) & 1 & $<0,0001^{* *}$ & $<0,0001^{* *}$ & $<0,0001^{* *}$ & $0,2828 \mathrm{~ns}$ & $<0,0001^{* *}$ & $0,0022^{* *}$ \\
\hline Concentração $(\mathrm{C})$ & 4 & $<0,0001 * *$ & $<0,0001^{* *}$ & $<0,0001 * *$ & $<0,0001 * *$ & $<0,0001 * *$ & $<0,0001^{* *}$ \\
\hline Interação A x C & 4 & $0,0241 *$ & $0,0049 * *$ & $<0,0001 * *$ & $0,0030 * *$ & $<0,0001 * *$ & $0,0037 * *$ \\
\hline $\mathrm{CV}(\%)$ & & 4,85 & 10,73 & 11,23 & 20,28 & 11,77 & 10,67 \\
\hline
\end{tabular}

*,**: Significativo $(\mathrm{p}<0,05$ e $\mathrm{p}<0,01)$ respectivamente pelo teste de Tukey.

Tabela 5. Resumo da análise de variância para os efeitos principais e suas interações, referente ao tratamento irrigado, avaliando os parâmetros emergência de plântula (EG), índice de velocidade de emergência (IVE), altura de plântula (AP), massa de matéria seca da parte aérea (MSPA), volume de raiz (VR) e massa de matéria seca de raiz (MSR).

Table 5. Summary of variance analysis for the main effects and their interactions, referring to irrigated treatment, evaluating seedling emergence (EG), emergence velocity index (IVE), seedling height (AP), shoot dry mass (MSPA), root volume (VR) and root dry mass (MSR).

\begin{tabular}{lcccccccccc} 
& \multicolumn{4}{c}{ EG } & IVE & AP & MSPA & VR & MSR \\
\cline { 2 - 7 } Fonte de variação & GL & P-valor & P-valor & P-valor & P-valor & P-valor & P-valor \\
\hline Ambiente de captura (A) & 1 & $0,0396^{*}$ & $0,2710 \mathrm{~ns}$ & $0,0002^{* *}$ & $0,0009^{* *}$ & $<0,0001^{* *}$ & $<0,0001^{* *}$ \\
Concentração (C) & 4 & $0,0014^{* *}$ & $<0,0001^{* *}$ & $<0,0001^{* *}$ & $<0,0001^{* *}$ & $<0,0001^{* *}$ & $<0,0001^{* *}$ \\
Interação A x C & 4 & $0,0674 \mathrm{~ns}$ & $0,0007^{* *}$ & $<0,0001^{* *}$ & $0,0050^{* *}$ & $<0,0001^{* *}$ & $<0,0001^{* *}$ \\
\hline CV $(\%)$ & & 15,31 & 17,18 & 11,54 & 17,33 & 15,52
\end{tabular}



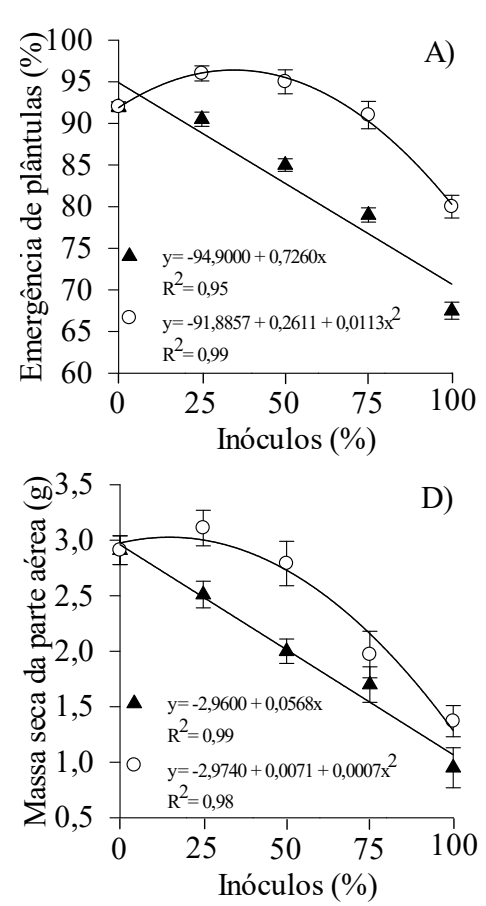

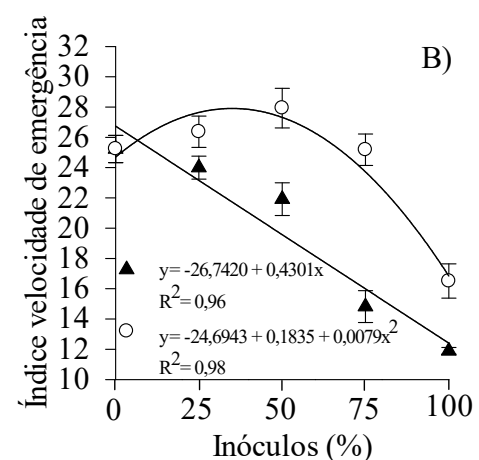

B)
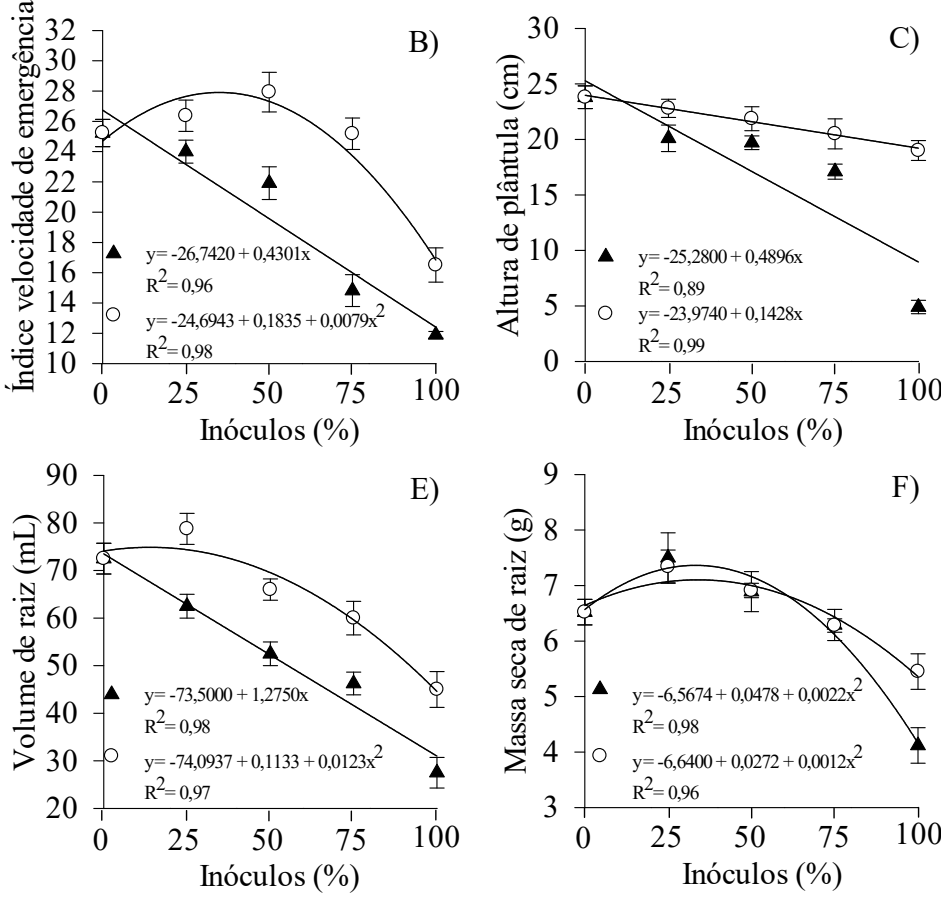

E)

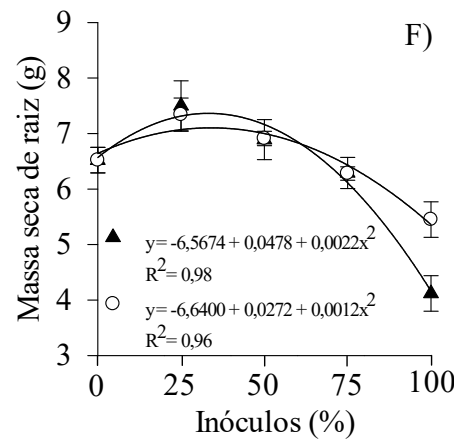

\section{- Inóculos da Mata}

Figura 1. Aplicação via inoculação dos microrganismos (inóculos) capturados de diferentes ambientes (mata e cana) em diferentes concentrações $(0,25 \%, 50 \%, 75 \%, 100 \%)$. Emergência de plântula (A), índice de velocidade de emergência (B), altura de plântula (C), massa seca da parte aérea (D), volume de raiz (E) e massa seca de raiz (F).

Figure 1. Application by inoculation of microorganisms (inoculations) captured from different environments (forest and sugarcane) in different concentrations $(0,25,50,75,100)$. Seedling emergence (A), emergence velocity index (B), seedling height (C), shoot dry mass (D), root volume (E) and root dry mass (F).
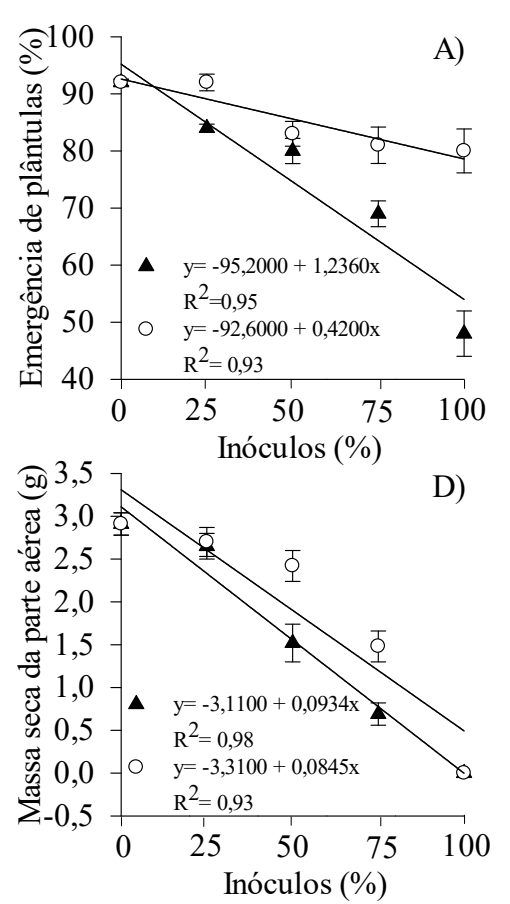
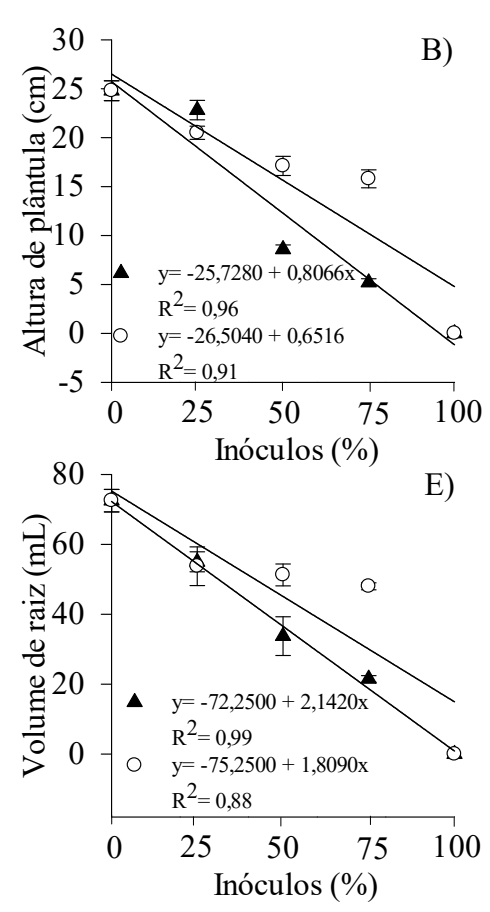

- Inóculo da Mata

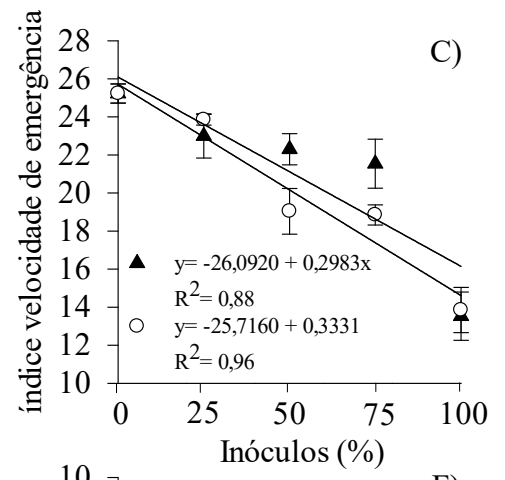

F)

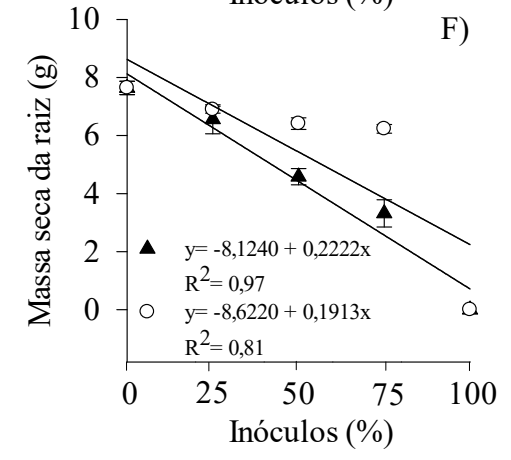

Figura 2. Aplicação via irrigação dos microrganismos (inóculos) capturados de diferentes ambientes (mata e cana) em diferentes concentrações $(0,25,50,75,100)$. Emergência de plântula (A), índice de velocidade de emergência (B), altura de plântula (C), massa de matéria seca da parte aérea (D), volume de raiz (E) e massa de matéria seca de raiz (F).

Figure 2. Application by irrigated of microorganisms (inoculations) captured from different environments (forest and sugarcane) in different concentrations $(0,25,50,75,100)$. Seedling emergence (A), emergence velocity index (B), seedling height (C), shoot dry mass (D), root volume (E) and root dry mass $(\mathrm{F})$. 


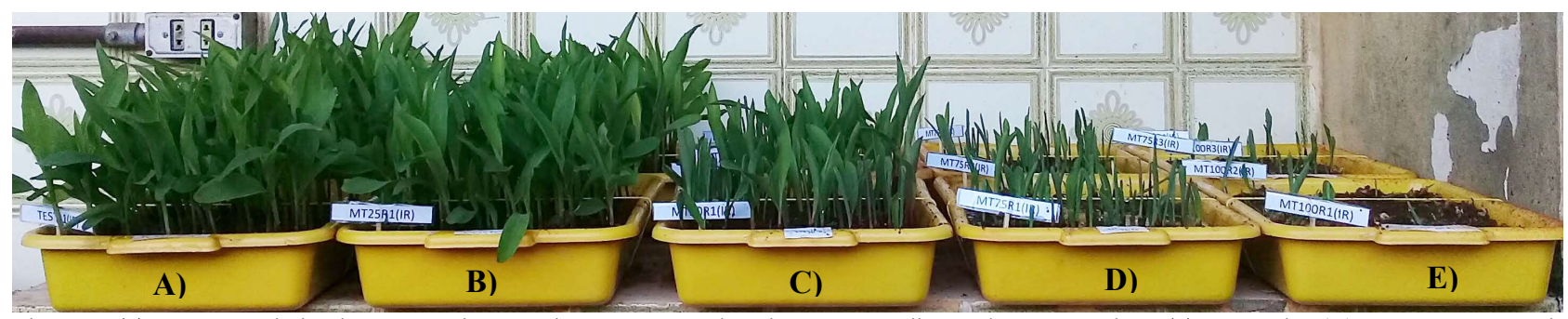

Figura 3. Tratamentos irrigados com microrganismos capturados da mata, 15 dias após a semeadura. Testemunha (A), concentrações de $25 \%$ (B), $50 \%$ (C), 75\% (D) e 100\% (E), respectivamente.

Figure 3. Irrigated treatments with microorganisms captured from the forest, 15 days after of sowing. Control (A), concentrations of $25 \%$ (B), $50 \%(C), 75 \%$ (D) and $100 \%$ (E), respectively.

\section{DISCUSSÃO}

Aspergillus spp. e Penicillium spp. são importantes fungos de pós-colheita em sementes de milho, responsáveis pela deterioração e comprometimento da germinação (HENNING et al., 2011). Porém, para o presente estudo não houve comprometimento na germinação e do índice velocidade de germinação das sementes independente do tratamento utilizado (Tabela 1), apresentando níveis exigidos para sua comercialização (BRASIL, 2013). Inferindo que as sementes não estavam infectadas, mas infestadas com os patógenos. Sementes infestadas com patógenos podem apresentar redução na germinação, vigor de sementes e até damping off de plântulas, por isso a desinfestação é decisiva na sanidade das sementes por agir diretamente na fonte do inóculo (TOMAZI et al., 2019), sendo necessário a busca por desinfetantes que promovam a sustentabilidade agrícola, como os microrganismos eficientes.

Em condições ótimas, patógenos como o Fusarium spp. são capazes de produzir metabólitos secundários tóxicos como as micotoxinas, o que acarretaria perda de rendimento no sistema produtivo, por inviabilizar a germinação de sementes e comprometer o vigor de plântulas (KRISHNAN et al., 2019).

Segundo Maximiano et al. (2018) quando realizado ou não pré-embebição de sementes de milho com água ozonizada em diferentes combinações de tempo e concentrações, a incidência de Fusarium spp. chegou a ser igual a $100 \%$, podendo ter sido favorecido pela água disponível na camada superficial das sementes. No presente estudo também foi observado o aumento na ocorrência de Fusarium spp., à medida que se aumentou a concentração de cada tratamento. No entanto, não se acredita que a umidade tenha sido decisiva para este caso, uma vez que o controle apresentou menor incidência quando comparada aos tratamentos. Uma possível explicação para esta relação é a presença de inóculos de Fusarium spp. associados aos microrganismos capturados, aumentando sua abundância e viabilizando sua competição por espaço e nutriente, podendo correlacionar com os baixos valores encontrados para o Aspergillus spp. e Penicillium spp. (Tabela 3).

Desta forma a utilização do presente inóculo não traria vantagens em relação a sanidade das sementes, pois, o aumento na incidência do Fusarium spp. comprometeria a produção do milho e outras culturas na área semeada.

Além disso, a utilização no inóculo pode ter potencializado microrganismos que competem com agentes de biocontrole responsáveis pela supressão do próprio Fusarium spp. (BERENDSEN et al., 2012). Em estudos realizados por Niu et al. (2017), foi observado que uma comunidade bacteriana simplificada associada a raiz do milho formada por sete cepas (Enterobacter cloacae, Stenotrophomonas maltophilia, Ochrobactrum pituitosum, Herbaspirillum frisingense, Pseudomonas putida, Curtobacterium pusillum e Chryseobacterium indologenes) entrou em colapso quando se retirou a cepa E. cloacae o que desestabilizou a proteção da planta contra o Fusarium verticillioides.

Espécies desse gênero como $F$. graminearum, $F$. accuminatum, F. esquiseti, F. proliferatum, F. avenaceum, F. solani e F. oxysporum são responsáveis pelas podridões radiculares em campos de soja, trigo e milho (PARIKH et al., 2018), ocasionando morte de plântulas (RAMOS et al., 2014), ou ainda atuando sob órgãos de reserva comprometendo a capacidade de germinação das sementes (KRISHNAN et al., 2019) e desenvolvimento de plântulas. Ao observar o decréscimo na emergência de plântula quando se aumenta a dosagem dos tratamentos, acredita-se que o Fusarium spp. pode ter sido um dos responsáveis para esta relação devido ao seu grau de patogenicidade, agravado ainda pelo aumentando de sua abundância oriunda dos tratamentos com maiores concentrações, uma vez que esses fungos podem sobreviver muito tempo no solo por meio de estruturas de resistência (RAMOS et al., 2014).

Os resultados apontam que a irrigação realizada na dosagem de $100 \%$ com microrganismos capturados da mata apresenta a menor porcentagem de emergência de plântulas, bem como para IVE. Segundo Vilela et al. (2011) solos em áreas de mata se caracterizam por uma grande riqueza e abundância de microrganismos. Estas interações são constituídas naturalmente com o meio selecionando seus indivíduos e fomentando o equilíbrio. No entanto, a alta aplicação desses microrganismos em ambientes que não possuem as mesmas características do ambiente de captura causa o desequilíbrio da microbiota já existente, acarretando severas mudanças em todo biofuncionamento, o que afeta diretamente a cultura de interesse.

Além disso, a presença de grande quantidade de microrganismos e os sais presentes no inóculo pode atuar como redutores dos potenciais hídricos do solo. Essa redução compromete o processo de germinação devido à menor absorção de água durante a embebição (BANSAL et al., 1980). Segundo Ghaderi-Far et al. (2010), a redução da disponibilidade de água junto a um possível efeito de sais pode influenciar diretamente na germinação, emergência, vigor e crescimento das plântulas.

Os microrganismos desempenham papel importante para estabilidade das plântulas por meio da degradação do revestimento das sementes, através da produção de enzimas, permitindo a absorção de água, oxigênio e a germinação 
(MOWA; MAASS, 2012). Porém a alta concentração de microrganismos revestindo as sementes foi determinante para o efeito negativo sobre o desenvolvimento de plântulas o que não foi observado sobre condições de laboratório, validando a existência de possíveis inóculos de Fusarium spp. ou de outros microrganismos prejudiciais e sua patogenicidade quanto ao meio inserido.

O tratamento via inoculação das sementes com microrganismos capturados da cana apresentou resultados satisfatórios em menores concentrações (25\% e $50 \%)$ se comparado com a testemunha, fato esse que não ocorreu para o inóculo da mata e tratamento via irrigação independe do ambiente de captura dos microrganismos.

Microrganismos eficientes de diferentes ambientes de captura podem apresentar composição microbiana diferente (SANTOS et al., 2020) e, consequentemente, diferentes respostas para uma mesma variável, ressaltando que a concentração do inóculo também é decisivo na obtenção desses resultados. Santos et al. (2020) evidenciaram que sementes embebidas em soluções de 1 e $2 \%$ de microrganismos eficientes capturados da área de mata promoveram maiores porcentagens de germinação e índice de velocidade de germinação em sementes de Urochloa brizantha $\mathrm{cv}$ Marandu se comparado com o tratamento de $100 \%$, e justifica esses resultados pela presença de microrganismos capazes de produzir fito-hormônios como giberelinas, auxinas, citocinas, ácido indolacético e ácido abscísico. Além da baixa abundância desses microrganismos nas menores concentrações, uma vez que mesmo considerando a produção benéfica de fito-hormônios, essas substâncias em altas doses tornam-se tóxicas ao desenvolvimento de plântulas.

A exposição das sementes a altas concentrações do inóculo pode comprometer a competição por nutrientes entre os microrganismos eficientes e o embrião da semente (SANTOS et al., 2020), interferindo negativamente no desenvolvimento de plântula. Esta relação poderia explicar porque os tratamentos irrigados inibiram totalmente $\mathrm{O}$ desenvolvimento de plântulas, uma vez que para essa condição houve uma maior carga de microrganismos aplicados no solo (Figura 2 e Figura 3). Desta forma, a utilização de dosagens contendo elevada carga microbiológica e o método de aplicação (inoculação ou irrigação), pode desordenar o ecossistema impossibilitando o equilíbrio entre raiz, solo e microrganismos.

Portanto a utilização de microrganismos eficientes estabelecendo apenas o método visual como identificação nem sempre proporciona resultados promissores, uma vez que estruturas de microrganismos causadores de doenças em plantas apresentam estruturas com cores similares aos de microrganismos benéficos, como o Fusarium graminearum que podem apresentar estruturas com coloração rosada (DARISSA et al., 2012).

\section{CONCLUSÕES}

A germinação e o índice de velocidade de germinação não foram comprometidos após a aplicação do inóculo de microrganismos e seus produtos da fermentação, provenientes de áreas de mata e cana-de-açúcar. Entretanto, os tratamentos mitigaram a incidência de Aspergillus spp. e Penicillium spp., quando comparado a testemunha, porém, uma relação inversa foi observada para o Fusarium spp.
A aplicação de microrganismos e seus produtos de fermentação afetam negativamente a emergência e desenvolvimento de plântulas de milho quando aplicados em altas concentrações, provavelmente por causar desequilíbrio da comunidade microbiana e sua relação com a planta.

\section{AGRADECIMENTOS}

A Coordenação de Aperfeiçoamento de Pessoal de Nível Superior - CAPES, em virtude do apoio financeiro. Ao Laboratório Central de Sementes e Mudas (LSCM) da Coordenadoria de Desenvolvimento Rural Sustentável -SP (CDRS). por ceder às sementes utilizadas nos ensaios.

\section{REFERÊNCIAS}

ACCINELLI, C.; MENCARELLI, M.; SACCÀ, M. L.; VICARI, A.; ABBAS, H. K. Managing and monitoring of Aspergillus flavus in corn using bioplastic-based formulations. Crop Protection, Guildford, v. 32, p. 3035 , 2012.

DOI:

https://dx.doi.org/10.1016/j.cropro.2011.10.006

BÁNKUTI, S. M. S.; BÁNKUTI, F. I. Gestão ambiental e estratégia empresarial: um estudo em uma empresa de cosméticos no brasil. Gestão \& Produção, São Carlos, v. 21 , n. 1, p. 171-184, 2014. DOI: http://dx.doi.org/10.1590/s0104-530x2014000100012

BANSAL, R. P.; BHATI, P. R.; SEN, D. N. Differential specificity in water imbibition of indian arid zone seeds. Biologia Plantarum, Praha, v. 22, n. 5, p.327-331, set. 1980. DOI: https://dx.doi.org/10.1007/bf02908976

BERENDSEN, R. L.; PIETERESE, C. M. J.; BAKKER, P. A. H. M. The rhizosphere microbiome and plant health. Trends In Plant Science, Oxford, v. 17, n. 8, p.478-486, 2012.

DOI: https://dx.doi.org/10.1016/j.tplants.2012.04.001

BRASIL_MINISTÉRIO DA AGRICULTURA, PECUÁRIA E DO ABASTECIMENTO. Instrução Normativa $\mathbf{n}^{\circ} \mathbf{4 5}$, de 17 de setembro de 2013. 22 p.

CALERO-HURTADO, A.; QUINTERO-RODRÍGUEZ, E.; PÉREZ-DÍAZ， A.; OLIVERA-VICIEDO， D.; PEÑA-CALZADA, K.; JIMÉNEZ-HERNÃNDEZ, J. Efecto entre microorganismos eficientes y fitomas-e en el incremento agroproductivo del frijol. Biotecnología En E1 Sector Agropecuario y Agroindustrial, Popayán, v. 17, n. 1, p. 20-33, 2019

CHAPARRO, J. M.; BADRI, D. V.; VIVANCO, J. M. Rhizosphere microbiome assemblage is affected by plant development. The ISME Journal, v. 8, n. 4, p.790-803, 2013. DOI: https://dx.doi.org/10.1038/ismej.2013.196

COLLA, L. M.; PRIMAZ, A. L.; LIMA, M.; BERTOLIN, T. E.; COSTA, J. A. V. Isolamento e seleção de fungos para biorremediação a partir de solo contaminado com herbicidas triazínicos. Ciência e Agrotecnologia, Lavras, v. 32, n. 3, p. 809-813, 2008. DOI: http://dx.doi.org/10.1590/s1413-70542008000300016

DARISSA, O.; ADAM, G.; SCHÄFER, W. A dsRNA mycovirus causes hypovirulence of Fusarium graminearum to wheat and maize. European Journal of Plant Pathology, Dordrecht, v. 134, n. 1, p. 181-189, 2012. DOI: https://dx.doi.org/10.1007/s10658-0129977-5

FERREIRA, E. P. B.; STONE, L. F.; MARTINDIDONET, C. C. G. Population and microbial activity of the soil under an agro-ecological production 
system. Revista Ciência Agronômica, Fortaleza, v. 48 , n. $1, \quad$ p. 22-31, 2017. DOI: https://dx.doi.org/10.5935/1806-6690.20170003

FU, L.; PENTON, R.; RUAN, Y.; SHEN, Z.; CHAO, X.; LI, R.; SHEN, Q. Inducing the rhizosphere microbiome by biofertilizer application to suppress banana Fusarium wilt disease. Soil Biology and Biochemistry, Elmsford, v. 104, p.39-48, 2017.2 DOI: https://dx.doi.org/10.1016/j.soilbio.2016.10.008

GHADERI-FAR, F.; GHEREKHLOO, J.; ALIMAGHAM, M. Influence of environmental factors on seed germination and seedling emergence of yellow sweet clover (Melilotus officinalis). Planta Daninha, Viçosa, v. 28, n. 3, p. 463-469, 2010. DOI: https://dx.doi.org/10.1590/s0100-83582010000300002

GIASSI, V.; KIRITANI, C.; KUPPER, K. C. Bacteria as growth-promoting agents for citrus rootstocks. Microbiological Research, Jena, v. 190, p.46-54, 2016.2 DOI: https://dx.doi.org/10.1016/j.micres.2015.12.006

HE, A.; KIU, J.; WNAG, X.; ZHANG, Q.; SONG, W.; CHEN, J. Soil application of Trichoderma asperellum GDFS1009 granules promotes growth and resistance to Fusarium graminearum in maize. Journal of Integrative Agriculture, v. 18, n. 3, p.599-606, 2019. DOI: https://dx.doi.org/10.1016/s2095-3119(18)62089-1

HENNING, F. A.; JACOB JUNIOR, E. A.; MERTZ, L. M.; PESKE, S. T. Qualidade sanitária de sementes de milho em diferentes estádios de maturação. Revista Brasileira de Sementes, v. 33, n. 2, p. 316-321, 2011. DOI: http://dx.doi.org/10.1590/s0101-31222011000200014

JANSSEN, E.; MOURITS, M. H. J.; FELS-KLERX, V. D.; LANSINK, A. O. Pre-harvest measures against Fusarium spp. Infection and related mycotoxins implemented by Dutch wheat farmers. Crop Protection, Guildford, v. 122, p. 1-34, $2019 . \quad$ DOI: https://dx.doi.org/10.1016/j.cropro.2019.04.005

KRISHNAN, N.; VELRAMAR, B.; VELU, R. K. Investigation of antifungal activity of surfactin against mycotoxigenic phytopathogenic fungus Fusarium moniliforme and its impact in seed germination and mycotoxicosis. Pesticide Biochemistry and Physiology, San Diego, v. 155, p. 101-107, 2019. DOI: https://dx.doi.org/10.1016/j.pestbp.2019.01.010

MAXIMIANO, C. V.; CARMONA, R.; SOUZA, N. O. S.; ALENCAR, E. R. de; BLUM, L. E. B. Physiological and sanitary quality of maize seeds preconditioned in ozonated water. Revista Brasileira de Engenharia Agrícola e Ambiental, Campina Grande, v. 22, n. 5, p. 360-365, 2018. DOI: https://dx.doi.org/10.1590/18071929/agriambi.v22n5p360-365

MOHAMMED, B. L.; HUSSEIN, R. A.; TOAMA, F. N. Biological control of Fusarium wilt in tomato by endophytic rhizobactria. Energy Procedia, v. 157, p. 171-179, 2019. https://dx.doi.org/10.1016/j.egypro.2018.11.178

MORAES, M. C. H. S.; MEDEIROS, E. V.; ANDRADE, D. S.; LIMA, L. D.; SANTOS, I. C. S.; MARTINS FILHO, A. P. Microbial biomass and enzymatic activities in sandy soil cultivated with lettuce inoculated with plant growth promoters. Revista Caatinga, Mossoró, v. 31, n. 4, p. 860-870, 2018. DOI: https://dx.doi.org/10.1590/1983-21252018v31n408rc
MOWA, E.; MAASS, E. The effect of sulphuric acid and effective micro-organisms on the seed germination of Harpagophytum procumbens (devil's claw). South African Journal of Botany, Pretoria, v. 82, p. 193-199, 2012. DOI: https://dx.doi.org/10.1016/j.sajb.2012.05.006

NIU, B.; PAULSON, J. N.; ZHENG, X.; KOLTER, R. Simplified and representative bacterial community of maize roots. Proceedings of the National Academy of Sciences of the United States of America, Washington, v. 114, n. 12, p. 2450-2459, 2017. DOI: https://dx.doi.org/10.1073/pnas.1616148114

PARIKH, L.; KODATI, S.; ESKELSON, M. J.; ADESEMOYE, A. O. Identification and pathogenicity of Fusarium spp. in row crops in Nebraska. Crop Protection, Guildford, v. 108, p. 120-127, 2018. DOI: https://dx.doi.org/10.1016/j.cropro.2018.02.019

PEDROZO, A.; OLIVEIRA, N. J. G.; ALBERTON, O. Biological nitrogen fixation and agronomic features of soybean (Glycine max (L.) Merr.) crop under different doses of inoculant. Acta Agronómica, Palmira, v. 67, n. 2, p.297-302, 2018.2 DOI: https://dx.doi.org/10.15446/acag.v67n2.56375

RAMOS, D. P.; BARBOSA, R. M.; VIEIRA, B. G. T. L.; PANIZZI, R. C.; VIEIRA, R. D. Infecção por Fusarium graminearum e Fusarium verticillioides em sementes de milho. Pesquisa Agropecuária Tropical, Goiânia, v. 44, n. 1, p. 24-31, 2014. DOI: https://dx.doi.org/10.1590/S1983-40632014000100011

SAVIĆ, Z.; DUDAŁ, T.; LOC, M.; GRAHOVAC, M.; BUDAKOV, D.; JAJIĆ, I.; KRSTOVIĆ, S.; BAROLEVIĆ, T.; KRSKA, R.; SULYOK, M. Biological Control of Aflatoxin in Maize Grown in Serbia. Toxins, v. $12, \quad$ n. 3 , p. 162, 2020. DOI: http://dx.doi.org/10.3390/toxins12030162

SANTOS, L. F.; LANA, R. P.; SILVA, M. C.; VELOSO, T. G..; KASUYA, M. C. M.; RIBEIRO, K. G. Effective microorganisms inoculant: diversity and effect on the germination of palisade grass seeds. Anais da Academia Brasileira de Ciências, v. 92, n. 1, p. 1-12, 2020. DOI: http://dx.doi.org/10.1590/0001-3765202020180426

TAHEUR, F. B.; KOUIDHI, B.; QURASHI, Y. M. A. A.; ABES, J. B. S; CHAIEB, K. Review: Biotechnology of mycotoxins detoxification using microorganisms and enzymes. Toxicon, Elmsford, v. 160, p. 12-22, 2019. DOI: https://dx.doi.org/10.1016/j.toxicon.2019.02.001

TOMAZI, Y.; BONOME, L. T. S.; SIQUEIRA, D. J.; MOURA, G. S.; FRANZENER, G. S. Métodos de assepsia em sementes de feijão. Revista Verde de Agroecologia e Desenvolvimento Sustentável, Pombal, v. 14, n. 2, p. 229-237, 2019. DOI: http://dx.doi.org/10.18378/rvads.v14i2.6353

USDA_UNITED STATES DEPARTAMENT OF AGRICULTURE. World Corn Harvest 2018/19 - 11 USDA Survey. Disponível em: <https://www.nass.usda.gov/Data_and_Statistics/inde x.php>. Acesso em: 23 jun. 2020.

VILELA, L.; MARTHA JUNIOR, G. B.; MACEDO, M. C. M.; MARCHÃO, R. L.; GUIMARÃES JUNIOR, R.; PULROLNIK, K.; MACIEL, G. A. Sistemas de integração lavoura-pecuária na região do Cerrado. Pesquisa Agropecuária Brasileira, Brasília, v. 46, n. 10, p. 1127-1138, 2011. DOI: https://doi.org/10.1590/S0100-204X2011001000003 